\title{
Theoretical and numerical study of strain rate influence on AA5083 formability
}

\author{
Cunsheng ZHANG, Lionel LEOTOING, Dominique GUINES, Eric RAGNEAU \\ INSA, Laboratoire de Génie Civil et Génie Mécanique (LGCGM, EA 3913) \\ 20 Av. des Buttes de Coësmes, 35043 Rennes Cedex, France \\ Email: lionel.leotoing@insa-rennes.fr \\ Tel : +33(0)2 $23238664 \quad$ Fax : +33(0)2 23238726
}

\begin{abstract}
With the application of new forming techniques (hydroforming, incremental forming), it is necessary to improve the characterization of the formability of materials and in particular the influence of strain rate. This paper begins with the characterization of material behavior of an aluminum alloy 5083 at high temperatures. To describe its visco-plastic behavior, Swift's hardening law is used and the corresponding parameter values are identified. Then, two different approaches are introduced to construct FLDs (forming limit diagrams) of this alloy sheet and evaluate the effect of the rate-sensitivity index on its formability. The first one is theoretical (the M-K model), and an algorithm is developed to calculate the limit strains by this model. In the second approach, the Marciniak test is simulated with the commercially available finite-element program ABAQUS. Based on FEM results, different failure criteria are discussed and an appropriate one is chosen to determine the onset of localized necking. With the material behavior data corresponding to AA5083 at $150^{\circ} \mathrm{C}$, parametric studies are carried out to evaluate the effect of the strain rate sensitivity index. The comparison of results by these two approaches shows the same tendency that an improvement of the formability with increasing strain rate sensitivity is observed. Finally, by consideration of the compensating effects of the strain
\end{abstract}


hardening and rate sensitivity indices, the FLDs of this sheet at $150^{\circ} \mathrm{C}, 240^{\circ} \mathrm{C}$ and $300^{\circ} \mathrm{C}$ are determined and compared. Results show that the formability of AA5083 seems not to be improved up to a certain temperature (between $240^{\circ} \mathrm{C}$ and $300^{\circ} \mathrm{C}$ ), above this temperature, the formability is greatly enhanced.

Key words: Forming Limit Diagrams (FLDs); Marciniak test; strain rate sensitivity

\section{Introduction}

The sheet metal forming receives more and more application in the domains of automotive and aeronautics. Especially with the innovative techniques, such as hydroforming and incremental forming, the manufacture of complex parts with low tools cost can be realized. These processes are generally performed in the intermediate range of strain rates $\left(10^{-2}\right.$ to $\left.500 \mathrm{~s}^{-1}\right)$. However, in sheet metal forming operations, the sheet can be deformed only to a certain limit that is usually imposed by the onset of localized necking, which eventually leads to fracture. A well-known method of describing this limit and predicting the occurrence of necking is the forming limit diagrams (FLDs) introduced by Keeler and Backofen in the 1960s [Keeler and Backofen(1963)]. In FLDs, a FLC (forming limit curve) represents a plot of major and minor available principal strains in the plane of the deformed sheet corresponding to the occurrence of the necking.

The determination of FLDs is a complex task, and research on FLDs has always been the subject of extensive experimental, theoretical and numerical studies. For experimental determination of FLDs, two main kinds of forming methods have been developed, the so-called out-of-plane stretching (e.g., the Nakazima test, the Hecker test) and the in-plane stretching (e.g., the Marciniak test). By forming a number of sheet specimens with varying widths, different 
strain states are obtained. The specimens are deformed to fracture and the strain state is evaluated just outside the fracture zone by the circle grid method or the digital image correlation technique. Finally, by connecting all the limit strain points, the FLC is drawn.

To effectively study plastic instability phenomenon and simplify the determination of FLDs, research has been mainly focused on development of the mathematical models for theoretical determination of FLDs. As early as in 1952, Swift [Swift(1952)] developed a criterion for predicting the onset of diffuse necking with the assumption that plastic instability occurs at a maximum load. However, in industrial stampings, the maximum allowable strain is determined by the localized necking rather than by diffuse necking. Hill [Hill(1952)] proposed a localized necking criterion based on the well-known zero extension assumption (for a negative minor strain), i.e., the localization band develops normal to the direction of zero extension in a sheet metal. On the basis of the experimental investigations concerning the strain localization of some specimens subjected to biaxial stretching, Marciniak and Kuczynski [Marciniak and Kuczynski(1967)] introduced in 1967 imperfections into sheets to allow necking to take place (known as the M-K model). The imperfections can be caused by factors such as local grain size variation, texture, alloys elements, thickness variation, etc. Today, the M-K model has been widely used to predict FLDs, and the original M-K method has undergone great improvement.

With increasing application of computational techniques, numerical predictions of FLDs have become more attractive and the finite element method (FEM) has been selected to simulate the Nakazima and Marciniak tests. In analyzing the simulation results for the onset of necking, it is essential to establish a failure criterion. One of the pioneers was Brun [Brun et al.(1999)Brun, Chambard, Lai, and De Luca] who has analyzed thinning of sheets in order to determine the onset of necking by the 
Nakazima method and construct FLDs for whole range of strain ratios. Basing on the same test, Geiger and Merklein [Geiger and Merklein(2003)] considered that the gradient of major strain changed rapidly when localized necking occurred. Using the limiting dome height (LDH) test, Narasimhan [Narasimhan(2004)] has predicted the onset of necking by the thickness strain gradient across neighboring regions. Additionally, the LDH test was carried out by Zadpoor et al. with ABAQUS into which an improved M-K model with Stören-Rice's analysis was implemented [Zadpoor et al.(2007)Zadpoor, Sinke, and Benedictus]. Predicted results showed that while the original M-K model considerably misspredicts the limit strains, a combination of the M-K model and Stören-Rice's analysis can predict the dome height with good accuracy. Based on the Marciniak test, Petek et al. [Petek et al.(2005)Petek, Pepelnjak, and Kuzman] put forward a new method for the evaluation of the thickness strain as a function of time as well as the first and second time derivative of the thickness strain. They proposed that the maximum of the second temporal derivative of thickness strain corresponds to the onset of necking. Volk [Volk(2006)] proposed a new approach for identifying the onset of localized necking by experimental and numerical methods. With calculated strain rates, the identification was carried out with the two following main effects: increase of points number with high strain rate (in the localization area) and decrease of the strain rate outside the localization bands. From the above literature, it is observed that FLDs strongly depend on the criteria chosen, therefore, an appropriate failure criterion is a key to numerical determination of FLDs.

Although FLDs have been successfully used and proved to be a powerful tool in sheet metal forming analysis, there are still shortcomings to be overcome. Firstly, to this day, there is not precise standard for the determination of FLDs. Moreover, it has been found that such forming limits change significantly with alterations in the strain path $[\operatorname{Arrieux}(1990)]$. To remove this limitation, a 
stress-based FLD as an alternative has proposed [Stoughton(2001)].

Additionally, relatively little attention has been paid to the models of FLDs taking the strain rate sensitivity into account. Strain hardening and strain rate sensitivity have been identified as important factors for determining formability of sheet metal and alter substantially the level and shape of FLCs. Experimentally, Laukonis and Ghosh [Laukonis and Ghosh(1978)] found that strain rate effect is very sensitive for AK steel, especially for the deformation mode near biaxial stretching, while aluminum seems to be insensitive to strain rate. Percy [Percy(1980)] analyzed the influence of strain rate on FLDs by explosive forming and concluded that FLDs level was dependent on the strain state and forming rates. Broomhead et al. [Broomhead and Grieve(1982)] performed bulge forming over a range of strain rates from $10^{-3}$ to $70 \mathrm{~s}^{-1}$ and concluded that the position of FLDs under biaxial tensile conditions decreased with increasing strain rate. These contradictory experimental results underline the difficulty in determining the onset of necking in the case of dynamic experiments. Hence, it is necessary to establish a rigorous procedure and carry out more experimental investigations about forming behavior at corresponding strain rates.

Theoretically, research on the rate sensitivity on FLDs has been carried out by several authors using the M-K model. Hutchinson et al. [Hutchinson et al.(1978)Hutchinson, Neale, and Needleman] predicted the FLDs with von Mises' yield function taking rate sensitivity into account. Their work has given important contributions to the insight into the influence of constitutive equations and plasticity theories on FLDs. Lee and Zaverl [Lee and Zaverl(1982)] computed entire FLD based on the rate-dependent flow theory under proportional loading with the assumption of zero extension. Barata Da Rocha et al. [Barata da Rocha et al.(1984-1985)Barata da Rocha, Barlat, and Jalinier] predicted the strain path-dependent FLDs by considering rate sensitivity and 
using Hill's theory of plastic anisotropy. Nie and Lee [Nie and Lee(1991)] calculated FLDs for rate sensitive materials by applying the isotropic hardening model of the flow theory for the anisotropic sheet metals. Graf and Hosford [Graf and Hosford(1990)] analyzed the effect of rate sensitivity on the righthand side of FLDs with the Logan's and Hosfords' anisotropy yield criterion. Today, for the right-hand side of the FLDs, the analysis has been quite successful, whereas to the left-hand side, because of the complex algorithms and lengthy calculations, relatively little attention has been paid.

Therefore, FLD's standardized determination, its new representations, its sensitives to strain paths and strain rate are still today's research points. Experimental results by tensile test at elevated temperatures $\left(150^{\circ} \mathrm{C}, 240^{\circ} \mathrm{C}\right.$ and $300^{\circ} \mathrm{C}$ ) show a strain rate dependence of aluminum alloy 5083 on temperature. In this paper, we are interested in the effect of this strain rate dependence on its formability. This effect is investigated by theoretical and numerical approaches. Firstly, an algorithm is developed to calculate the limit strains with the M-K model. Then, the Marciniak test is simulated for this rate-dependent material with the commercially available finite-element program ABAQUS. Finally, based on the above two methods, the effect of rate sensitivity index on formability is evaluated and FLDs of AA5083 sheet at various temperatures are determined.

\section{Strain rate sensitivity of aluminum alloy 5083}

Increased interest in the production of lightweight vehicles to improve fuel economy has resulted in an interest in utilization of aluminum alloys. In particular, because of its relatively good formability and corrosion resistance, the aluminum-magnesium alloy 5083 receives more and more application in automotive and aerospace industry. Previous studies have shown the strain rate dependence of the alloy at elevated temperature 
[Diot et al.(2006)Diot, Guines, Gavrus, and Ragneau]. Hence in this paper, the multiplicative Swift law

$$
\bar{\sigma}=K\left(\bar{\varepsilon}_{0}+\bar{\varepsilon}\right)^{n} \dot{\bar{\varepsilon}}^{m}
$$

has been chosen to describe the visco-plastic behavior of this AA5083 alloy, where $\bar{\varepsilon}$ and $\dot{\bar{\varepsilon}}$ are the equivalent plastic strain and the equivalent plastic strain rate, respectively. Here, $n$ and $m$ are the strain hardening and strain rate sensitivity indices, and $K$ and $\bar{\varepsilon}_{0}$ are material parameters.

To characterize the high temperature deformation behavior of AA5083, tensile tests have been performed on a high-speed servo-hydraulic testing machine (DARTEC, 20kN capacity) at temperatures of $150^{\circ} \mathrm{C}, 240^{\circ} \mathrm{C}$ and $300^{\circ} \mathrm{C}$ and the constant crosshead speeds of 1.56, 15.6 and $156 \mathrm{~mm} / \mathrm{s}$ (corresponding to intermediate strain rates from approximately $10^{-2}$ up to $10 \mathrm{~s}^{-1}$ ), respectively.

By the tensile tests, the true stress-true strain curves at $150^{\circ} \mathrm{C}, 240^{\circ} \mathrm{C}$ and $300^{\circ} \mathrm{C}$ are obtained as shown in Fig.1, Fig.2 and Fig.3, respectively. With the least squares method, the corresponding parameter values of above constitutive material model have been identified to fit experimental data as shown in Tab.1. Here, $K, n$ and $m$ are considered to be constant for a given temperature and $m$ is determined basing on the stress-strain curves with the three speeds at this temperature. One can observe that AA5083 exhibits little strain rate sensitivity at $150^{\circ} \mathrm{C}(\mathrm{m}=0.0068)$, while this sensitivity clearly augments with increase of temperature. On the contrary, with increasing temperature the work hardening index $n$ decreases. The corresponding fitting curves are compared with experimental stress-strain curves in Fig.1, Fig.2 and Fig.3, respectively.

At $150^{\circ} \mathrm{C}$, it is observed that the curves identified with Swift's law are in good agreement with experimental data. On the contrary, at higher temperatures, some divergences between experimental and identified curves can 
be observed, especially for lower forming speeds. The experimental curves decline from the peak as strain proceeds, while Swift's fitting curves always give increasing trends. The declination of flow stress with strain after reaching the peak stress is mainly attributed to material softening [Lee et al.(2004)Lee, Sohn, Kang, Suh, and Lee]. Of particular interest for us here is the effect of strain rate sensitivity on the forming capacity of sheets, therefore, in this work, softening effect is not considered.

\section{$3 \quad$ M-K theoretical model}

\subsection{Brief description of the $M-K$ model}

The typical M-K geometrical model is shown in Fig.4. The imperfection is geometrically represented by a long groove which is characterized by an initial imperfection factor

$$
f_{0}=\frac{e_{0}^{b}}{e_{0}^{a}}<1,
$$

where $e_{0}^{a}$ and $e_{0}^{b}$ are the initial sheet thicknesses in zone $a$ and zone $b$, and throughout the analysis the indices $a$ and $b$ are used to designate the zones outside and inside the groove, respectively.

In the M-K original model introduced by Marciniak and Kuczynski [Marciniak and Kuczynski(1967)], the groove is perpendicular to the principal stress, i.e., $\Psi_{0}=0$. Later, Hutchinson et al. [Hutchinson et al.(1978)Hutchinson, Neale, and Needleman] extended this model to strain paths in the negative minor strain region based on a groove inclined at an angle $\Psi_{0}$ with respect to the principal axis-2 (Fig.4). They put forward that the limit strains under uniaxial tension varied with initial groove orientation, as well 
as current orientation. For anisotropic materials, Barata Da Rocha [Barata da Rocha et al.(1984-1985)Barata da Rocha, Barlat, and Jalinier] also concluded that in most cases the critical strains were achieved for initial groove orientations different from zero. For the right side of FLDs, many researchers achieved critical strains with the simplistic model $\Psi_{0}=0$. Banabic and Dannenmann [Banabic and Dannenmann(2001)] applied Hill's 1993 yield criterion in the M-K model and analyzed the influence of the yield curve shape upon the right-hand side of FLDs. Avila and Vieira [Avila and Vieira(2003)] developed an algorithm for prediction of the right-hand side of FLDs based on the M-K model. Five different yield criteria (von Mises', Hill's 1948, Hill's 1979, Hosford's and Hill's 1993) were implanted into this algorithm to analyze their influence on FLDs.

In the following work, the numerical analysis of the M-K model for both cases ( $\Psi_{0}=0$ and $\Psi_{0} \neq 0$ ) is illustrated. For the left-hand side of FLDs, the case $\Psi_{0} \neq 0$ (general case) is considered, while $\Psi_{0}=0$ (particular case) is for the right-side of FLDs.

Thanks to the sheet plane quasi-isotropy of AA5083, von Mises's yield function under plane stress assumption $\left(\sigma_{13}^{k}=\sigma_{23}^{k}=\sigma_{33}^{k}=0\right)$ can be used to model this sheet behavior

$$
\left(\bar{\sigma}^{k}\right)^{2}=\left(\sigma_{11}^{k}\right)^{2}-\sigma_{11}^{k} \sigma_{22}^{k}+\left(\sigma_{22}^{k}\right)^{2}+3\left(\sigma_{12}^{k}\right)^{2}
$$

where $\bar{\sigma}^{k}$ is the equivalent stress, $\sigma_{11}^{k}, \sigma_{22}^{k}$ and $\sigma_{12}^{k}$ are stress tensor components, $k=a($ or $b)$.

The sheet metal obeys Levy-Mises' flow rule, which can be expressed in the form

$$
\Delta \varepsilon_{i j}^{k}=\frac{\partial \bar{\sigma}^{k}}{\partial \sigma_{i j}^{k}} \Delta \bar{\varepsilon}^{k} \quad(\mathrm{i}, \mathrm{j}=1,2),
$$

where $\Delta \varepsilon_{i j}^{k}$ and $\Delta \bar{\varepsilon}^{k}$ are the strain component increments and the equivalent plastic strain increments, respectively, and $\Delta$ refers to a change correspond- 
ing to a small time increment $\Delta t$. In addition, incompressibility condition is assumed during this analysis.

In the M-K model, the same force in the direction-n (Fig. 4) is transmitted across zones $a$ and $b$. Therefore, the equilibrium equations are

$$
\sigma_{n n}^{a} e^{a}=\sigma_{n n}^{b} e^{b}, \quad \sigma_{n t}^{a} e^{a}=\sigma_{n t}^{b} e^{b},
$$

where $e^{a}, e^{b}$ are the current sheet thicknesses.

The strain in zone $b$, parallel to the groove, is constrained by the uniform zone $a$ so that the compatibility condition is

$$
\Delta \varepsilon_{t t}^{a}=\Delta \varepsilon_{t t}^{b}
$$

\subsection{Particular case (positive minor strain)}

The initial imperfection is assumed to be perpendicular to the principal axis$1, \Psi_{0}=0$, in the particular case considered here. The groove reference and main axes system coincide for both zones. The eqs.(5) and (6) reduce to

$$
\sigma_{11}^{a} e^{a}=\sigma_{11}^{b} e^{b}
$$

and

$$
\Delta \varepsilon_{22}^{a}=\Delta \varepsilon_{22}^{b}
$$

For the sake of convenience, the notations

$$
\begin{aligned}
& \rho^{k}=\frac{\Delta \varepsilon_{22}^{k}}{\Delta \varepsilon_{11}^{k}}, \quad \quad \Omega^{k}=\frac{\sigma_{22}^{k}}{\sigma_{11}^{k}}=\frac{2 \rho^{k}+1}{2+\rho^{k}} \\
& \varphi^{k}=\frac{\bar{\sigma}^{k}}{\sigma_{11}^{k}}=\sqrt{1-\Omega^{k}+\left(\Omega^{k}\right)^{2}}, \quad \Phi^{k}=\frac{\Delta \bar{\varepsilon}^{k}}{\Delta \varepsilon_{11}^{k}}=\frac{2 \varphi^{k}}{2-\Omega^{k}}
\end{aligned}
$$


related to von Mises' yield function are introduced.

The equivalent strain rate can be expressed in terms of the strain and time increments as

$$
\dot{\bar{\varepsilon}}^{k}=\frac{\Delta \bar{\varepsilon}^{k}}{\Delta t}
$$

With Swift's hardening law (1), the flow rule (4) and the eqs.( $8-10)$, the eq.(7) can be expressed as

$$
\left(\bar{\varepsilon}_{0}+\bar{\varepsilon}^{a}+\Phi^{a} \Delta \varepsilon_{11}^{a}\right)^{n} \frac{\left(\varphi^{a}\right)^{m-1}}{\left(2 \Omega^{a}-1\right)^{m}}=f\left(\bar{\varepsilon}_{0}+\bar{\varepsilon}^{b}+\Phi^{b} \Delta \varepsilon_{11}^{b}\right)^{n} \frac{\left(\varphi^{b}\right)^{m-1}}{\left(2 \Omega^{b}-1\right)^{m}},
$$

where $f$ is the current imperfection factor. Equation (11) shows that with the disappearance of time increment, the level of strain rate has no effect in the M-K model. Therefore, only the rate-sensitivity vis-à-vis the parameter $m$ could be analyzed for a given strain rate.

Under the assumption of proportional loading in zone $a$, the strain path is characterized by a constant strain ratio $\rho^{a}$. The parameter $\Delta \varepsilon_{11}^{a}$ is known. Therefore the terms $\Omega^{k}, \varphi^{k}$ and $\Phi^{k}$ are constant for a certain $\rho^{a}$ and can be easily calculated. For zone $b$ the corresponding quantities vary with the strain increments but all can be expressed as functions of $\Delta \varepsilon_{11}^{b}$ by use of the compatibility condition.

To calculate $\Delta \varepsilon_{11}^{b}$, the function

$F\left(\Delta \varepsilon_{11}^{b}\right)=\left(\bar{\varepsilon}_{0}+\bar{\varepsilon}^{a}+\Phi^{a} \Delta \varepsilon_{11}^{a}\right)^{n}\left(\frac{2 \Omega^{b}-1}{2 \Omega^{a}-1}\right)^{m}-f\left(\bar{\varepsilon}_{0}+\bar{\varepsilon}^{b}+\Phi^{b} \Delta \varepsilon_{11}^{b}\right)^{n}\left(\frac{\varphi^{b}}{\varphi^{a}}\right)^{m-1}$

is used. To numerically solve the equation $F\left(\Delta \varepsilon_{11}^{b}\right)=0$, Newton-Raphson's method is used. The $(i+1)$ th iteration step is

$$
\left(\Delta \varepsilon_{11}^{b}\right)^{(i+1)}-\left(\Delta \varepsilon_{11}^{b}\right)^{(i)}=-\frac{F\left(\left(\Delta \varepsilon_{11}^{b}\right)^{(i)}\right)}{d F / d\left(\left(\Delta \varepsilon_{11}^{b}\right)^{(i)}\right)}
$$

When absolute values of the increment $\left(\Delta \varepsilon_{11}^{b}\right)^{(i)}$ become less than an error 
$E$, the solution of $\Delta \varepsilon_{11}^{b}$ is achieved. Then $\Delta \bar{\varepsilon}^{b}$ is calculated. Thus, for every increment $\Delta \varepsilon_{11}^{a}$ a strain increment $\Delta \bar{\varepsilon}^{b}$ is obtained iteratively. Before performing the next step of the computations, the strains associated with the zone $a$ and $b$ are updated by adding the corresponding increments. The computation is stopped when the failure criterion is satisfied $\left(\Delta \bar{\varepsilon}^{b} / \Delta \bar{\varepsilon}^{a} \geq 7\right)$ and the corresponding strains $\varepsilon_{11}^{a}$ and $\varepsilon_{22}^{a}$ at this moment are retained as the limit strains. This point corresponds to a particular strain path defined by the coefficient $\rho^{a}$. In order to obtain other points on FLDs, the computations described above must be performed in a loop controlled by this parameter.

\subsection{General case (negative minor strain)}

In the general case, the initial imperfection is inclined at an angle $\Psi_{0}$ with respect to the principal axis-2. As the inherent model equations are based on the groove reference system, the calculation of $\Delta \bar{\varepsilon}^{b}$ is more complicated for $\Psi_{0} \neq 0$ than for $\Psi_{0}=0$.

The groove rotation is also updated with the increment of the plastic strain [Butuc et al.(2003)Butuc, Gracio, and Barata da Rocha], which is described by

$$
\tan (\Psi+\Delta \Psi)=\frac{1+\Delta \varepsilon_{11}^{a}}{1+\Delta \varepsilon_{22}^{a}} \tan \Psi
$$

Using the transformation matrix, the stress and strain states in the main axes system are changed to the groove system of coordinates. In zone $a$, there are not shear stress and strain components, i.e. $\sigma_{12}^{a}=0$ and $\Delta \varepsilon_{12}^{a}=0$. With the notation $\delta=\sigma_{12}^{b} / \sigma_{11}^{b}$, the equilibrium conditions (5) and compatibility equation (6) can be written as 


$$
\begin{aligned}
& \frac{\left(\bar{\varepsilon}_{0}+\bar{\varepsilon}^{a}+\Delta \bar{\varepsilon}^{a}\right)^{n}}{\varphi^{a}}\left(\Delta \bar{\varepsilon}^{a}\right)^{m}\left(\cos ^{2} \Psi+\Omega^{a} \sin ^{2} \Psi\right)= f \frac{\left(\bar{\varepsilon}_{0}+\bar{\varepsilon}^{b}+\Delta \bar{\varepsilon}^{b}\right)^{n}}{\varphi^{b}}\left(\Delta \bar{\varepsilon}^{b}\right)^{m} \\
& \cdot\left(\cos ^{2} \Psi+\Omega^{b} \sin ^{2} \Psi+2 \delta \sin \Psi \cos \Psi\right) \\
& \frac{\left(\bar{\varepsilon}_{0}+\bar{\varepsilon}^{a}+\Delta \bar{\varepsilon}^{a}\right)^{n}}{\varphi^{a}}\left(\Delta \bar{\varepsilon}^{a}\right)^{m}\left(\Omega^{a}-1\right) \sin \Psi \cos \Psi= f \frac{\left(\bar{\varepsilon}_{0}+\bar{\varepsilon}^{b}+\Delta \bar{\varepsilon}^{b}\right)^{n}}{\varphi^{b}}\left(\Delta \bar{\varepsilon}^{b}\right)^{m} \\
& \cdot\left(\left(\Omega^{a}-1\right) \sin \Psi \cos \Psi+\delta\left(\cos ^{2} \Psi-\sin ^{2} \Psi\right)\right) \\
& \Delta \varepsilon_{11}^{a}\left(\sin ^{2} \Psi+\rho^{a} \cos ^{2} \Psi\right)=\frac{\Delta \bar{\varepsilon}^{b}}{2 \varphi^{b}}\left(\left(2-\Omega^{b}\right) \sin ^{2} \Psi+\left(2 \Omega^{b}-1\right) \cos ^{2} \Psi-12 \delta \sin \Psi \cos \Psi\right) .
\end{aligned}
$$

There are three unknowns $\Delta \bar{\varepsilon}^{b}, \Omega^{b}$ and $\delta$ in above three equations, which form the non-linear system

$$
\left\{\begin{array}{l}
F_{1}\left(\Delta \bar{\varepsilon}^{b}, \Omega^{b}, \delta\right)=0 \\
F_{2}\left(\Delta \bar{\varepsilon}^{b}, \Omega^{b}, \delta\right)=0 \\
F_{3}\left(\Delta \bar{\varepsilon}^{b}, \Omega^{b}, \delta\right)=0 .
\end{array}\right.
$$

To solve this system of equations (15), Newton-Raphson's method is used. When the absolute values of the increments $\Delta \bar{\varepsilon}^{b}, \Omega^{b}$ and $\delta$ become less than an error $E$, the solution corresponding to this increment is achieved. As soon as the failure criterion is satisfied, the corresponding strain $\varepsilon_{11}^{a}$ and $\varepsilon_{22}^{a}$ are identified as the limit strains. The analysis is repeated for different values of $\Psi_{0}$ between $0^{\circ}$ and $90^{\circ}$, and the limit point on the FLDs is obtained after minimization of $\varepsilon_{11}^{a}$ with respect to $\Psi_{0}$. Repeatition of the above procedure for other strain paths give corresponding points on the FLCs.

The results based on this approach will be discussed in the last section of this paper. To validate this approach, the numerical simulation of Marciniak test will be carried out in the following. 


\section{Numerical method}

\subsection{FE model}

In this part, the Marciniak test is chosen to numerically analyze the formability of sheet metal. The finite-element model for the Marciniak test is composed of a rigid cylindrical punch with a flat bottom, a die and a deformable sheet. In addition, a pressure load is directly applied on the sheet as the blank-holder force (Fig.5). Here, the use of a pressure rather than simply fixing the blank edge is to be as a counterpart in future experiments.

To assure the occurrence of maximal strains on the central part of the blank, the specimens are designed especially with a reduced central thickness (1 mm), compared to the thickness of the sheet $(2.0 \mathrm{~mm})$ as shown in Fig.6.

The Marciniak test requires the application of various specimen geometries for the determination of different strain states, ranging from uniaxial through plane strain to balanced biaxial. In the present paper, the geometry and dimensions of specimen are shown in Fig.7 and Tab.2.

The analysis is carried out with the commercially available finite-element program ABAQUS with shell linear elements S4R. Due to symmetrical boundary conditions, only the quarter of the entire model is simulated. The elasticity of the specimen is defined with a Young's modulus of $70000 \mathrm{MPa}$ and a Poisson's ratio of 0.3. The constitutive law (1) is implemented into ABAQUS by using an UHARD user subroutine.

The contact interaction is modeled using Coulomb's law: friction coefficient for punch-blank is 0.05 ; while blank-die friction value is chosen to 0.5 . The speed of the punch during the stamping procedure is $5 \mathrm{~m} / \mathrm{s}$. 


\subsection{Failure criterion}

Hereafter, we take the specimen No.2 in Tab.2 as an example to illustrate the analysis process. The rheological parameter values used in this simulation correspond to the material behavior data of AA5083 at $150^{\circ} \mathrm{C}$ with $m=0.01$. These values serve also as a basis for the following parametric studies.

Because the occurrence of the plastic instabilities is determined by localized necking whose size is of the order of the sheet thickness, the thickness strain can be used in a local criterion to evaluate the occurrence of necking (CRIT1). If the necking occurs, a sharp change of thickness strain can be observed, then sheet metal will suffer drastic deformation (Fig.8). This plastic instability corresponds to a bifurcation point, i.e. the intersection point of two bifurcation branches. When a sharp change of thickness strain cannot be clearly observed, as shown in Fig.9, a polynomial curve fitting method is employed. Here, $f_{1}(t)$ and $f_{2}(t)$ are two 3rd-degree polynomial functions and represent the fitting curves of the two branches, respectively. Then time coordinate $t_{1}$ of the intersection point is calculated. Based on the FEM results, the major and minor strains at this moment are obtained by linear interpolation of the closer calculated strain values. Due to the reduced thickness of the central part, the maximum thickness strain generally first occurs at the center of the sheet (Fig.10). Moreover, after the onset of necking, the level of strain remains constant in the other adjacent elements.

In order to choose an appropriate criterion for the detection of necking, two additional local criteria are evaluated: maximum second strain derivative (CRIT2) and equivalent plastic strain increment ratio (CRIT3). For CRIT2, the occurrence of the sharp variation of thickness strain is considered as the onset of localized necking and then the second temporal derivative of thickness strain must present a peak at this moment. According to Petek's method [Petek et al.(2005)Petek, Pepelnjak, and Kuzman], the second tem- 
poral derivatives of thickness strain are calculated for whole forming time, and its peak vis-à-vis the process time is evidently defined as the onset of necking. For CRIT3, the same method as the M-K model is used. First the average equivalent plastic strain is calculated over all five integration points in the sheet thickness. When the equivalent plastic strain increment ratio in the localized element and its adjacent one attains 7, the major and minor strains in the adjacent one are noted as the limit strains. The same procedure is repeated for different geometries and the corresponding limit strains describe the forming limit curve. The limit strains determined based on these three local criteria are represented in Fig.11. The comparison reveals good agreement between these three approaches. Due to its ease of use, in this paper, CRIT3 is chosen to analyze the onset of localized necking.

In Fig.12, strain paths corresponding to several deformation modes are plotted. These numerical paths are quasi-linear, which is in accordance with the linear strain path hypothesis in the theoretical M-K model.

\section{Results and discussion}

\subsection{Determination of an appropriate imperfection factor $f_{0}$}

As it is well known, the M-K model is sensitive to the initial imperfection factor $f_{0}$. Generally, the value of the initial imperfection factor $f_{0}$ is chosen to make the best fit between the theoretical results and experimental or numerical results. Here, in order to choose an appropriate factor, the FLCs by the M-K model with various $f_{0}$ and by FEM are shown in Fig.13. As it is seen from this figure, $f_{0}$ has a great influence on the determination of FLCs. By comparison, when $f_{0}=0.998$, there is the best agreement between the FLCs determined by the theoretical and numerical approaches. The detail comparison is displayed 
in Fig.14. Hence, for the studied material, $f_{0}$ is set to 0.998 .

\subsection{Effect of the strain rate sensitivity index $m$ on FLCs}

To evaluate the effect of the strain rate sensitivity index on FLCs, a study is performed with a changed value of $m$ in Swift's hardening law. For the M-K model, five different values of $m$ are used while for FEM we choose $m=0.01$ and $m=0.04$.

As illustrated in Fig.15, the influence of the strain rate sensitivity $(m)$ on FLCs determined by the M-K model can be clearly observed: a high $m$ value produces a high level of FLC. However, the left-hand side is more sensitive to the parameter $m$ than the right-hand side of FLCs. For example, in comparison with $m=0.01$, the formability for $m=0.04$ is enhanced by $73 \%, 67 \%$ and $12 \%$ under uniaxial tension, plane strain and equi-biaxial stretching, respectively.

Numerical FLDs determined by FEM in Fig.16 display the same tendency as the M-K model: increase of the strain rate sensitivity coefficient improves the formability of the modelled material. Moreover, the comparison shows good agreement in FLDs of various values of $m$ determined by FEM and by the M-K model with the identified imperfection factor $f_{0}(0.998)$.

\subsection{Effect of the strain hardening index $n$ on FLCs}

To investigate the effect of hardening index $n$, Swift's hardening law with various values of $n$ is employed by the M-K model.

Fig. 17 presents the effect of the hardening index $n$ on FLCs. The comparison indicates that the index $n$ has a profound influence on the level of FLDs. As seen in this figure, the material formability is improved with increasing 
value of $n$. For example, in comparison with $n=0.1$, an increase of $134.9 \%$ in formability under plane strain condition can be observed for $n=0.25$.

\subsection{Determination of FLDs for the AA5083 sheet}

From the above analysis, both the strain hardening and rate sensitivity indices improve the formability of sheet metals. However, for AA5083, Tab.1 demonstrates that with increasing temperature, the strain hardening index decreases while the rate sensitivity index increases. Hence, at elevated temperatures, the effect of the rate sensitivity on the formability will compensate that of the strain hardening index. Taking these compensating effects into account, we investigate the formability of AA5083 sheet by theoretical and numerical approaches.

Figure ?? shows the FLCs determined by these two approaches. Because of the compensating effects of the two indices, there is no clear difference in the left-hand side of theoretical FLCs between $150^{\circ} \mathrm{C}$ and $240^{\circ} \mathrm{C}$, while for the right-hand side, FLC at $150^{\circ} \mathrm{C}$ is slightly higher than that at $240^{\circ} \mathrm{C}$. On the contrary, FLC at $300^{\circ} \mathrm{C}$ is always higher than those at other temperatures in the whole range of strain path. For example, in comparison with the formability at $150^{\circ} \mathrm{C}$, there are increases of $55 \%, 33 \%$ and $3 \%$ under uniaxial tension, plane strain and equi-biaxial stretching at $300^{\circ} \mathrm{C}$, respectively.

Hence, for this alloy, the formability seems not to be improved up to a certain temperature (between $240^{\circ} \mathrm{C}$ and $300^{\circ} \mathrm{C}$ ), above this temperature, the formability is greatly enhanced. 


\section{Conclusion}

In this paper, the sheet formability is investigated by the theoretical M-K model and by a numerical method. For the numerical method, the difficulty is to establish a pertinent criterion for detecting the onset of necking. The proposed criterion, similarly to that in the M-K model, is based on the equivalent plastic strain increment ratio in the localized element and its adjacent one. Moreover, this criterion predicts the onset of localized necking with the principal strains, therefore it is easy to use for experimental determination of FLDs. Then from the comparison between the theoretical and numerical results, an appropriate initial imperfection factor of the M-K model is identified $\left(f_{0}=0.998\right)$. By means of parametric studies based on the above two approaches, the effect of strain hardening index $n$ and the rate sensitivity index $m$ on FLCs are observed: the formability is increased with increase of $n$ and $m$. Finally, by consideration of the compensating effects of the strain hardening and rate sensitivity indices, FLDs of AA5083 sheet are constructed by the M-K model and by FEM. Results show that the formability of this alloy seems not to be improved up to a certain temperature, above this temperature, the formability is greatly enhanced.

The results must be experimentally validated in order to determine accurate FLDs necessary and optimize the forming processes in which the strain rate sensitivity should be considered. This validation is in progress by means of a dynamic Marciniak test associated with a high speed camera and the digital image correlation technique to detect the onset of localized necking and construct FLDs. 


\section{References}

[Arrieux(1990)] Arrieux, R., 1990. Détermination théorique et expérimentale des courbes limites de formage en contraintes. Ph.D. thesis, INSA de Lyon.

[Avila and Vieira(2003)] Avila, A. F., Vieira, E., 2003. Proposing a better forming limit diagram prediction - a comparative study. Journal of Materials Processing Technology 141, 101-108.

[Banabic and Dannenmann(2001)] Banabic, D., Dannenmann, E., 2001. Prediction of the influence of yield locus on the limit strains in sheet metals. Journal of Materials Processing Technology 109, 9-12.

[Barata da Rocha et al.(1984-1985)Barata da Rocha, Barlat, and Jalinier] Barata da Rocha, A., Barlat, F., Jalinier, J., 1984-1985. Prediction of the forming limit diagrams of anisotropic sheets in linear and non-linear loading. Materials Science and Engineering 68, 151-164.

[Broomhead and Grieve(1982)] Broomhead, P., Grieve, R., 1982. The effect of strain rate on the strain to fracture of a sheet steel under biaxial tensile stress conditions. Journal of Engineering Materials and Technology 104, 102-106.

[Brun et al.(1999)Brun, Chambard, Lai, and De Luca] Brun, R., Chambard, A., Lai, M., De Luca, P., 1999. Actual and virtual testing techniques for a numerical definition of materials. In: Proceedings of NUMISHEET '99, Besançon, France. pp. 393-398.

[Butuc et al.(2003)Butuc, Gracio, and Barata da Rocha] Butuc, M., Gracio, J., Barata da Rocha, A., 2003. A theoretical study on forming limit diagrams prediction. Journal of Materials Processing Technology 142, 714-724.

[Diot et al.(2006)Diot, Guines, Gavrus, and Ragneau] Diot, S., Guines, D., Gavrus, A., Ragneau, E., 2006. Forming process of a 5083 aluminium alloy. constitutive model covering a large range of temperature. International Journal of Forming Processes 9, 167-188. 
[Geiger and Merklein(2003)] Geiger, M., Merklein, M., 2003. Determination of forming limit diagrams - a new analysis method for characterization of materials' formability. Annals of the CIRP 52, 213-216.

[Graf and Hosford(1990)] Graf, A., Hosford, W., 1990. Calculations of forming limit diagrams. Metallurgical Transactions A 21A, 87-93.

[Hill(1952)] Hill, R., 1952. On discontinuous plastic states, with special reference to localized necking in thin sheets. Journal of the Mechanics and Physics of Solids $1,19-30$.

[Hutchinson et al.(1978)Hutchinson, Neale, and Needleman] Hutchinson, J., Neale, K., Needleman, A., 1978. Mechanics of sheet metal forming. New York/London, Plenum Press, pp. 269-285.

[Keeler and Backofen(1963)] Keeler, S., Backofen, W., 1963. Plastic instability and fracture in sheets stretched over rigid punches. Trans. ASM 56, 25-48.

[Laukonis and Ghosh(1978)] Laukonis, J., Ghosh, A., 1978. Effects of strain path changes on the formability of sheet metals. Metallurgical Transactions A 9A, $1849-1856$.

[Lee and Zaverl(1982)] Lee, D., Zaverl, F., 1982. Necking growth and forming limits in sheet metals. International Journal of Mechanical Sciences 24, 157-173.

[Lee et al.(2004)Lee, Sohn, Kang, Suh, and Lee] Lee, M., Sohn, S., Kang, C., Suh, D., Lee, S., 2004. Effects of pre-treatment conditions on warm hydroformability of 7075 aluminum tubes. Journal of Materials Processing Technology 155-156, $1337-1343$.

[Marciniak and Kuczynski(1967)] Marciniak, Z., Kuczynski, K., 1967. Limit strains in the processes stretch-forming sheet metal. International Journal of Mechanical Sciences 9, 609-620.

[Narasimhan(2004)] Narasimhan, K., 2004. A novel criterion for predicting forming limit strains. In: Ghosh, S., Castro, J., Lee, J. (Eds.), Materials Processing and Design: Modeling, Simulation and Applications. NUMIFORM 2004 Proceedings 
of the 8th International Conference on Numerical Methods in Industrial Forming Processes. Vol. 2. American Institute of Physics, pp. 850-855.

[Nie and Lee(1991)] Nie, Q., Lee, D., 1991. The effect of rate-sensitivity on history dependent forming limit of anisotropic sheet metals. Journal of Materials Shaping Technology 9, 233-240.

[Percy(1980)] Percy, J., 1980. The effect of strain rate on the FLD for sheet metal. Annals of the CIRP 29, 151-152.

[Petek et al.(2005)Petek, Pepelnjak, and Kuzman] Petek, A., Pepelnjak, T., Kuzman, K., 2005. An improved method for determining forming limit diagram in the digital enviroment. Journal of Mechanical Engineering 51, 330-345.

[Stoughton(2001)] Stoughton, T., 2001. Stress-based forming limits in sheet-metal forming. Journal of Engineering Materials and Technology 123, 417-422.

[Swift(1952)] Swift, H., 1952. Plastic instability under plane stress. Journal of the Mechanics and Physics of Solids 1, 1-18.

[Volk(2006)] Volk, W., 2006. New experimental and numerical approach in the evaluation of the FLD with the FE-method. In: Proceedings of the FLC-Zurich 06, Zurich, Switzerland.

[Zadpoor et al.(2007)Zadpoor, Sinke, and Benedictus] Zadpoor, A., Sinke, J., Benedictus, R., 2007. Prediction of limit strains in limiting dome height formability test. In: Cueto, E., Chinesta, F. (Eds.), 10th ESAFORM conference on material forming. American Institute of Physics, pp. 258-263. 
Table 1

\begin{tabular}{|c|c|c|c|c|}
\hline$T\left({ }^{\circ} \mathrm{C}\right)$ & $K(\mathrm{MPa})$ & $\bar{\varepsilon}_{0}$ & $n$ & $m$ \\
\hline 150 & 500.870 & 0.00044 & 0.2307 & 0.0068 \\
\hline 240 & 328.062 & 0.00126 & 0.1275 & 0.0280 \\
\hline 300 & 207.207 & 0.00035 & 0.0614 & 0.0657 \\
\hline
\end{tabular}

Constitutive model parameter values

\begin{tabular}{|c|c|c|c|c|c|c|c|c|c|c|}
\hline Specimen No. & 1 & 2 & 3 & 4 & 5 & 6 & 7 & 8 & 9 & 10 \\
\hline $\mathrm{W}(\mathrm{mm})$ & 10 & 30 & 35 & 40 & 45 & 48 & 50 & 60 & 80 & 100 \\
\hline $\mathrm{R}(\mathrm{mm})$ & \multicolumn{10}{|c|}{50} \\
\hline $\operatorname{Rc}(\mathrm{mm})$ & \multicolumn{10}{|c|}{10} \\
\hline $\operatorname{Re}(\mathrm{mm})$ & \multicolumn{10}{|c|}{10} \\
\hline
\end{tabular}

Table 2

Specimen dimensions used in simulation

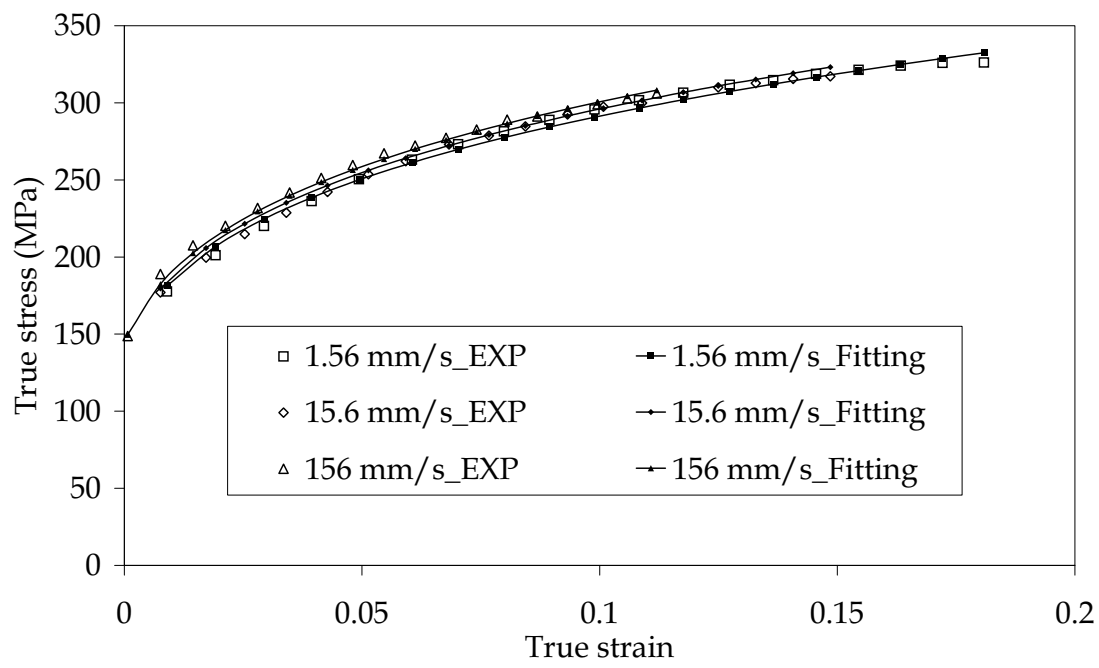

Figure 1. Experimental and fitting stress-strain curves at $150^{\circ} \mathrm{C}$ 


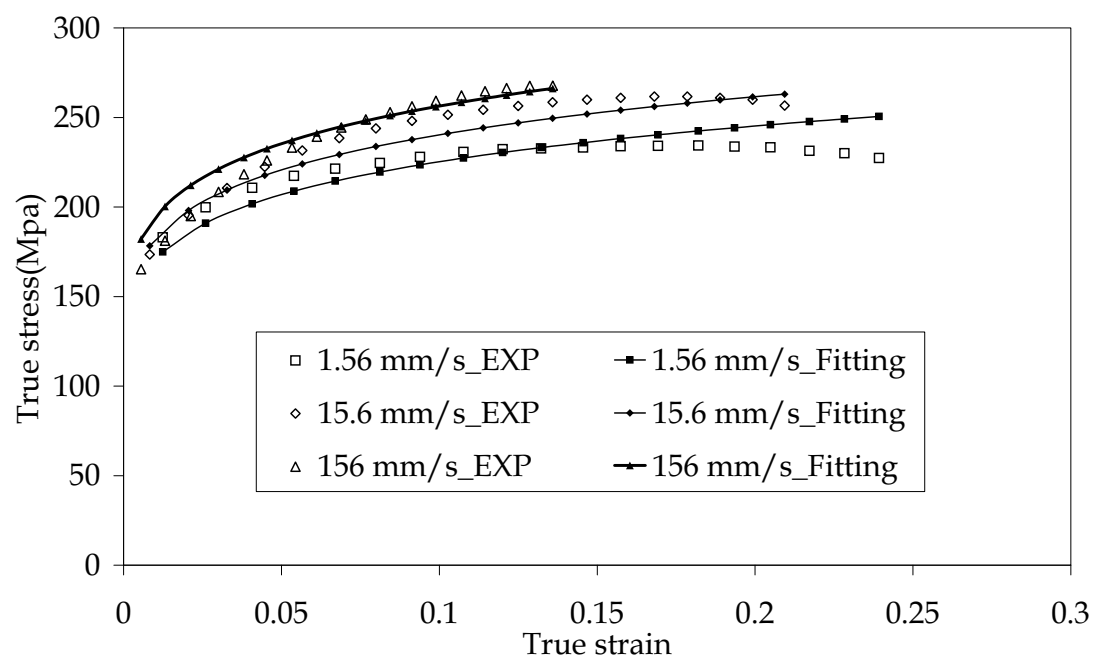

Figure 2. Experimental and fitting stress-strain curves at $240^{\circ} \mathrm{C}$

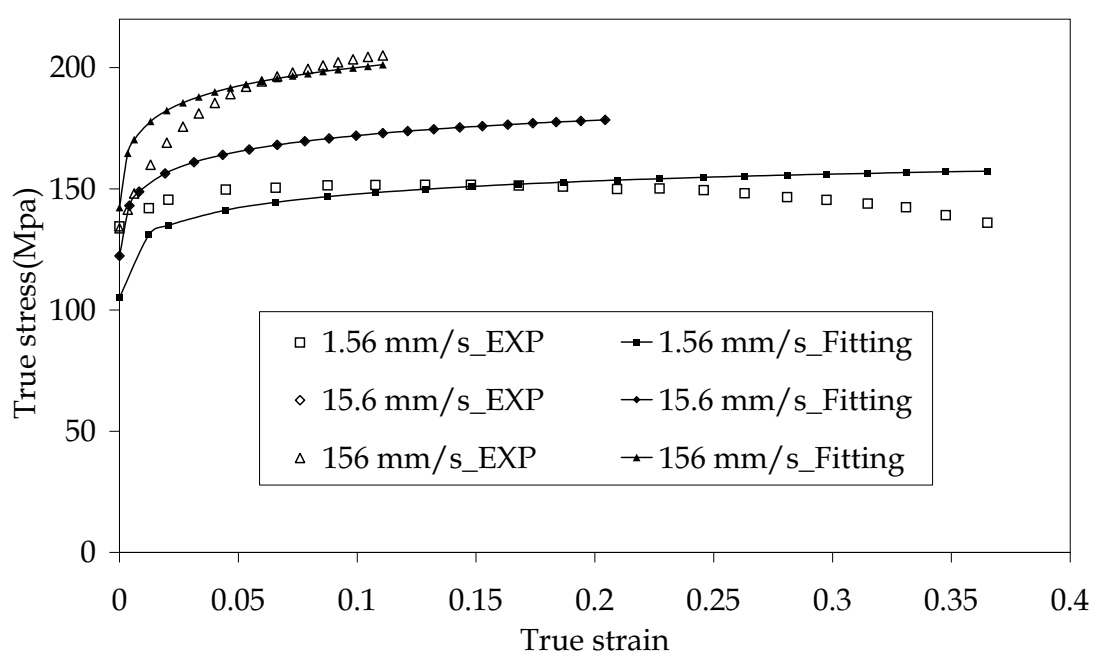

Figure 3. Experimental and fitting stress-strain curves at $300^{\circ} \mathrm{C}$ 


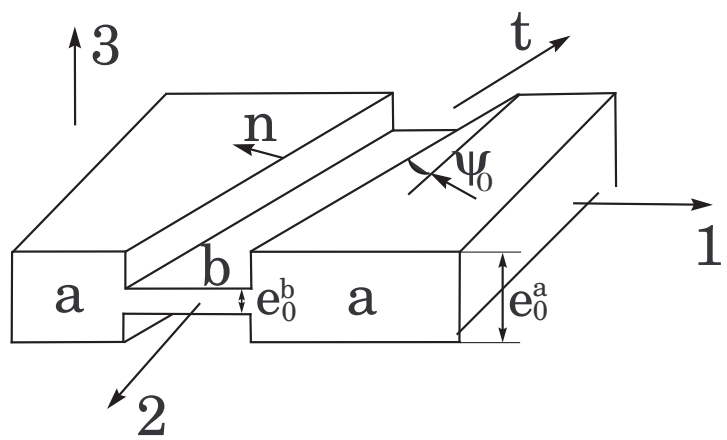

Figure 4. M-K model with an inclined groove $\left(\Psi_{0}\right)$

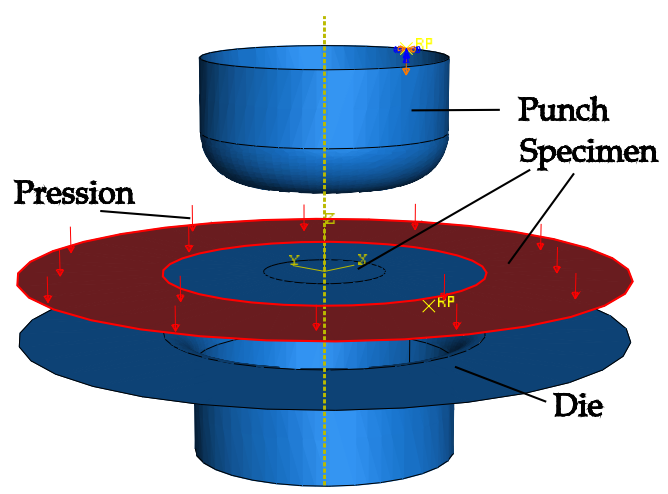

Figure 5. FE model of the Marciniak test

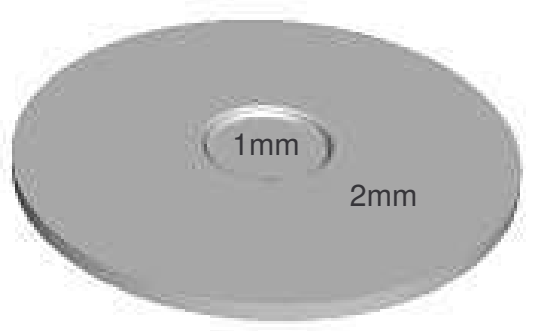

Figure 6. A blank with the reduced section thickness 


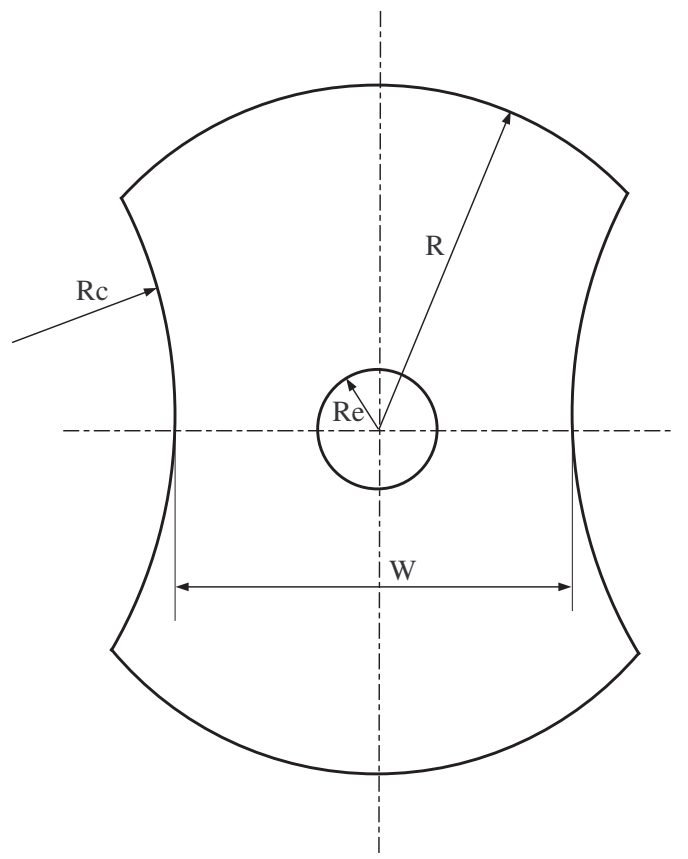

Figure 7. Specimen geometry in the Marciniak test

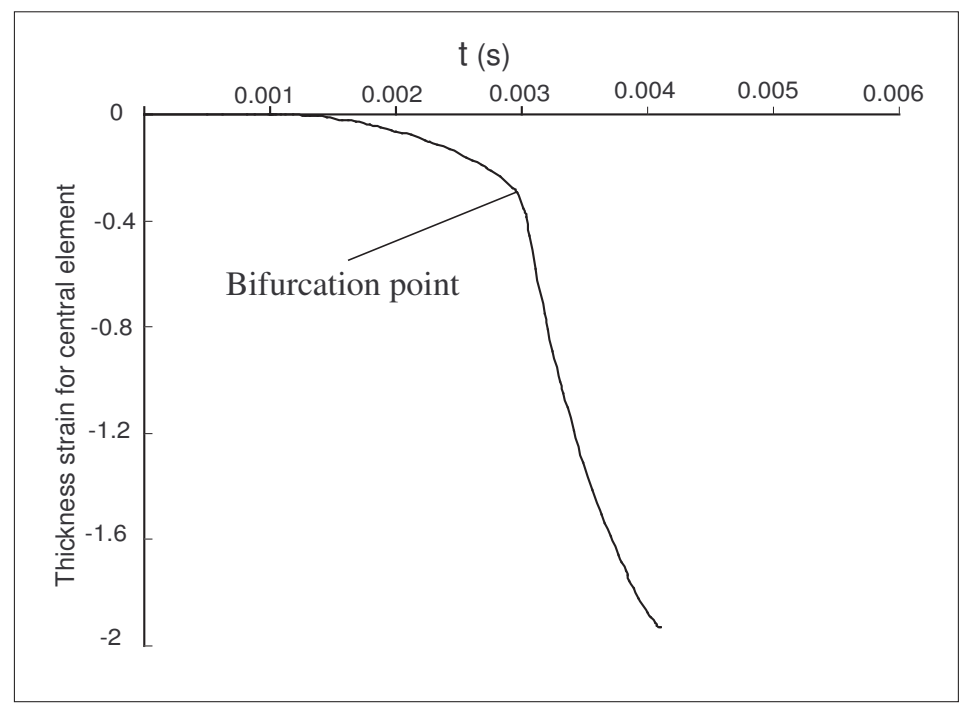

Figure 8. Evolution of thickness strain of central element and detection of the onset of necking 


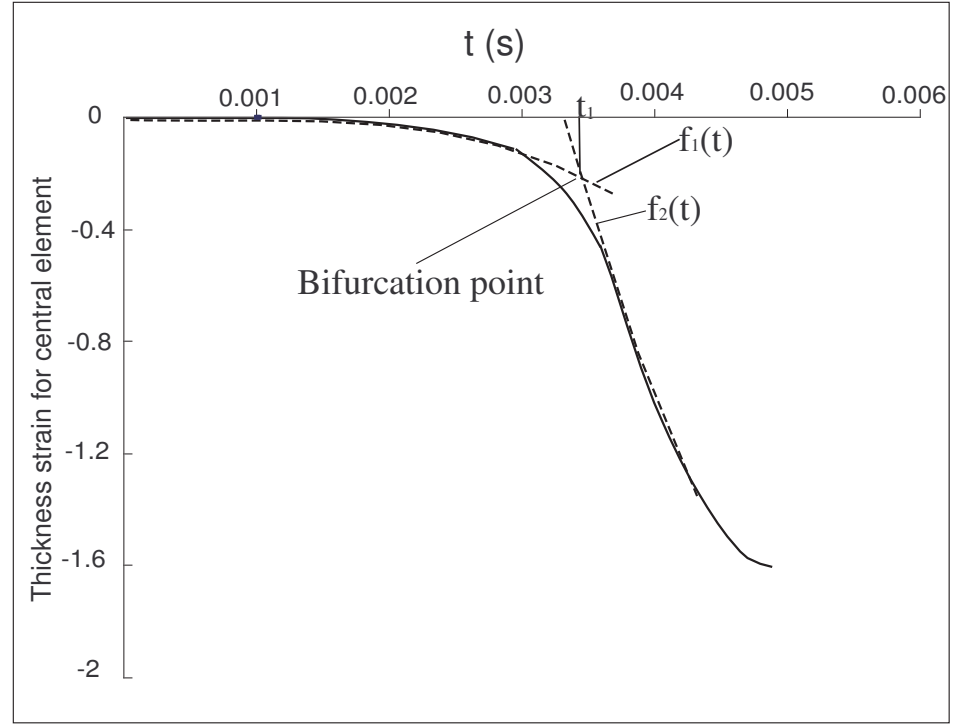

Figure 9. Determination of bifurcation point by the polynomial fitting method

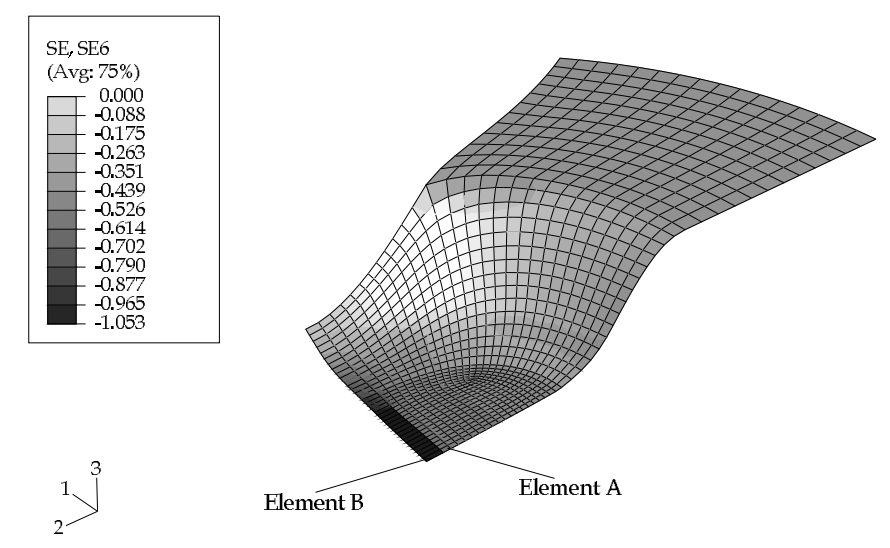

Figure 10. Thickness strain distribution of the specimen No.2 (Tab.2) 


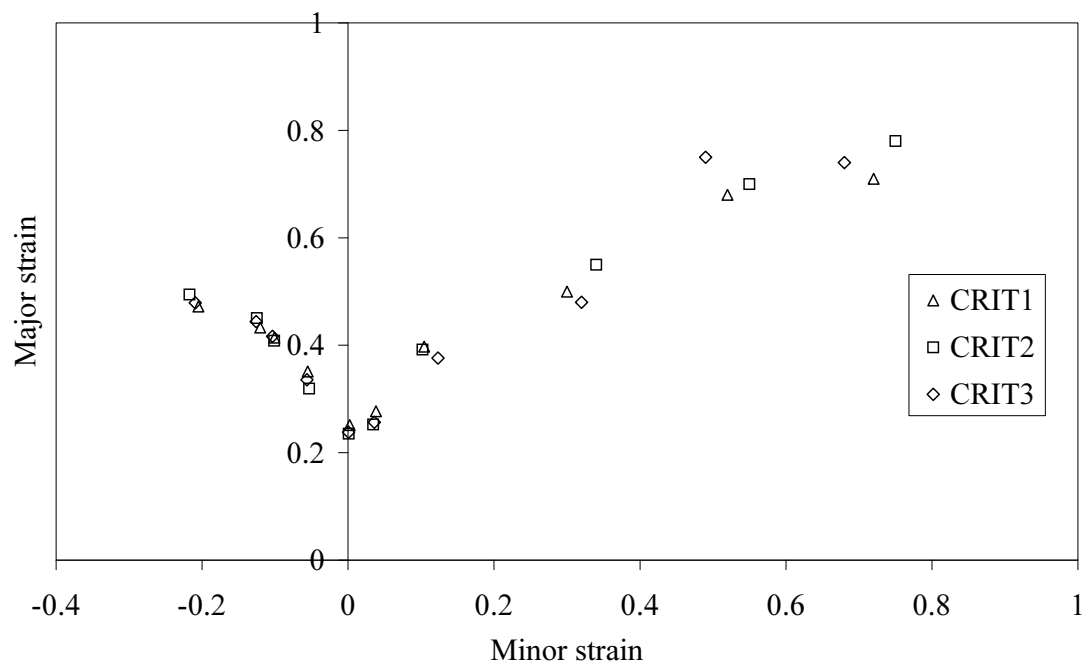

Figure 11. Limit strains determined by FEM with various failure criteria

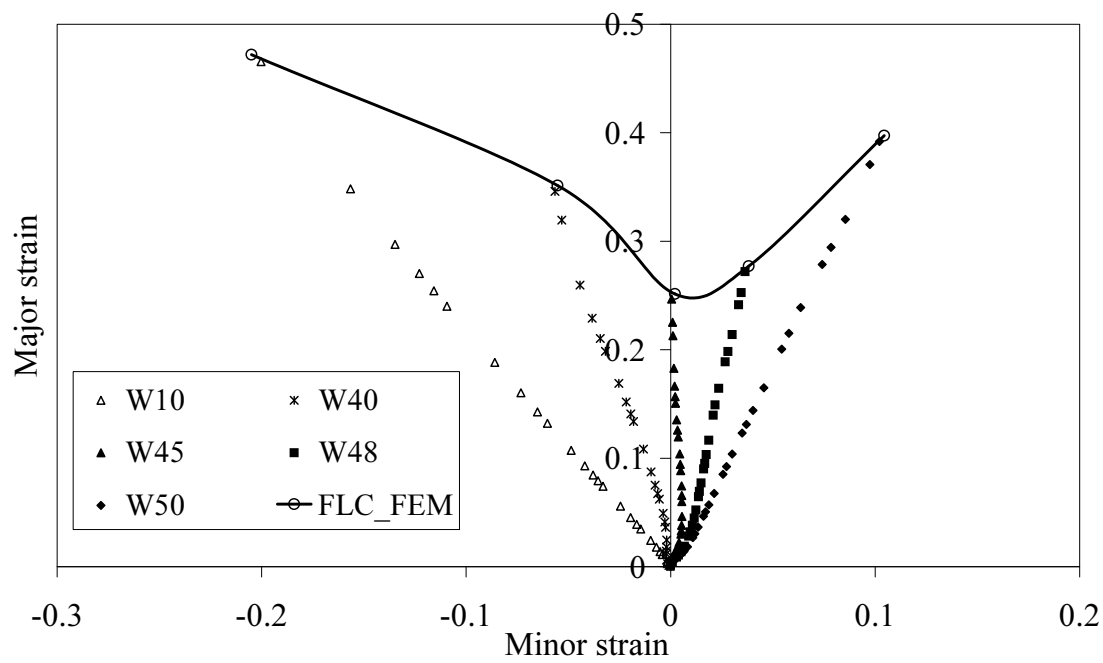

Figure 12. Strain paths corresponding to different deformation modes by FEM 


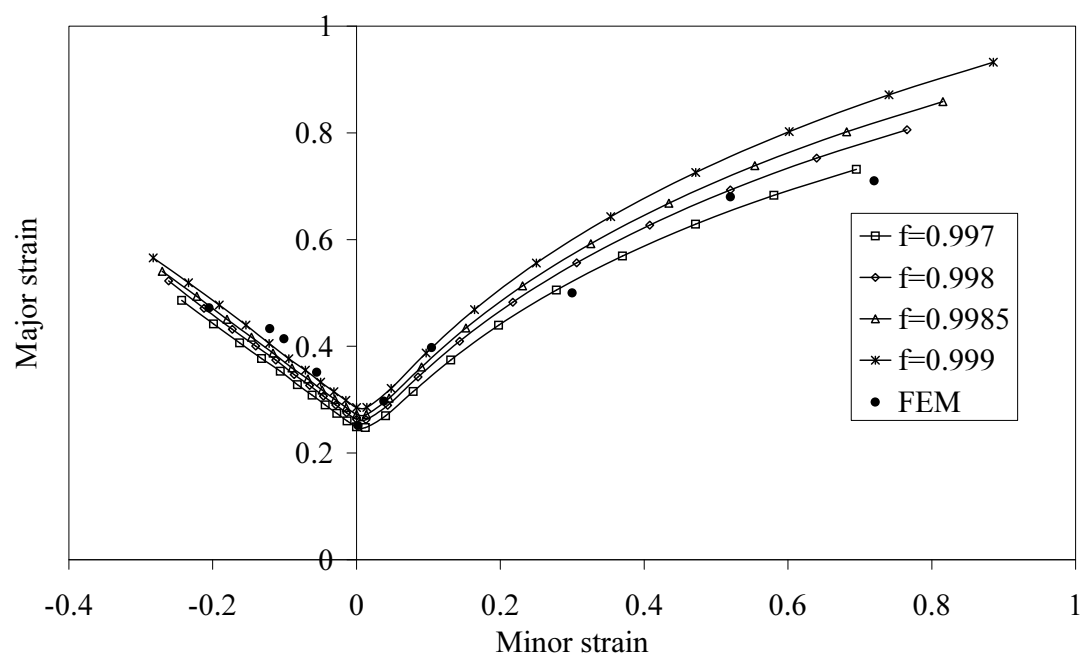

Figure 13. Comparison of FLDs by the M-K model with various initial imperfection factors and by FEM

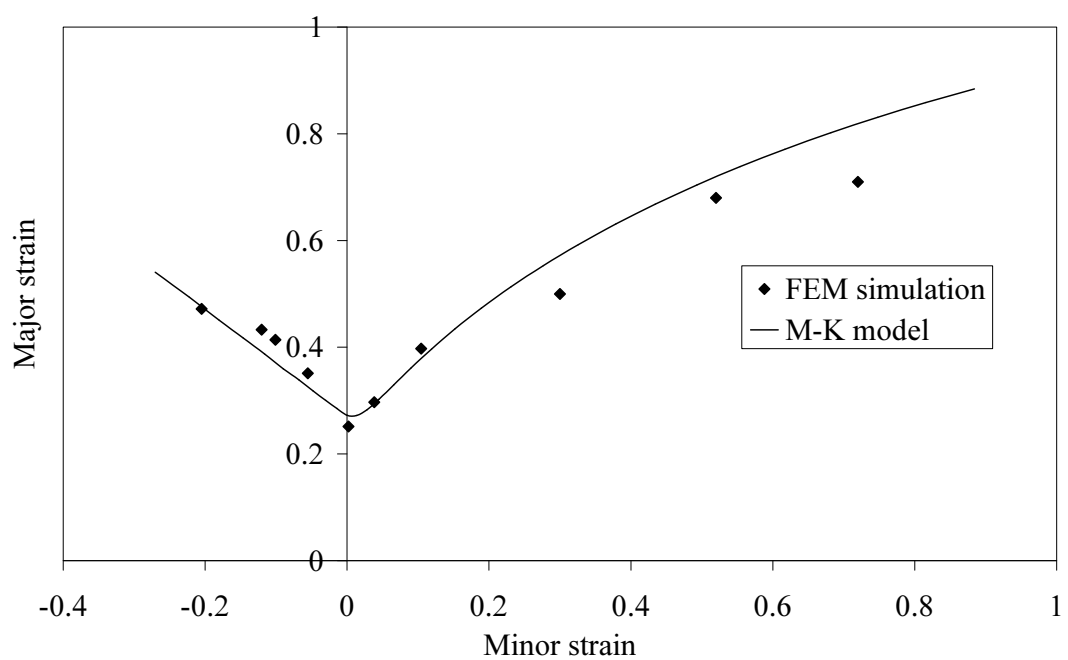

Figure 14. FLDs determined by the M-K model and by FEM $\left(f_{0}=0.998\right)$ for $\mathrm{m}=0.01$ 


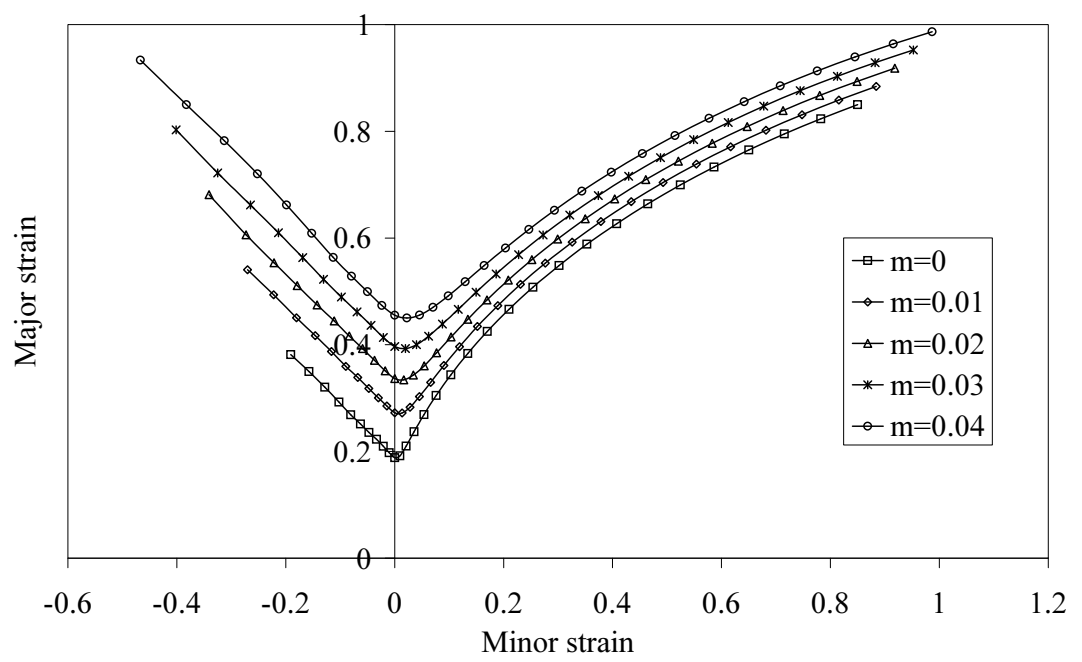

Figure 15. Effect of rate sensitivity index $m$ on FLCs by the M-K model

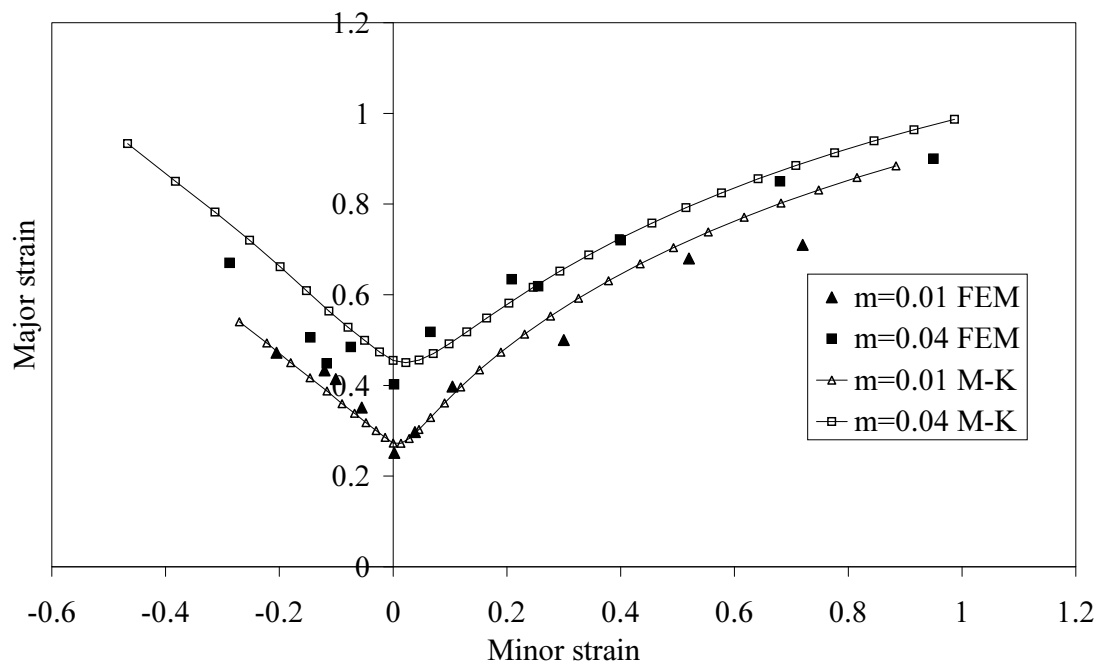

Figure 16. Comparison of effect of the rate sensitivity index on FLCs by the M-K model and by FEM 


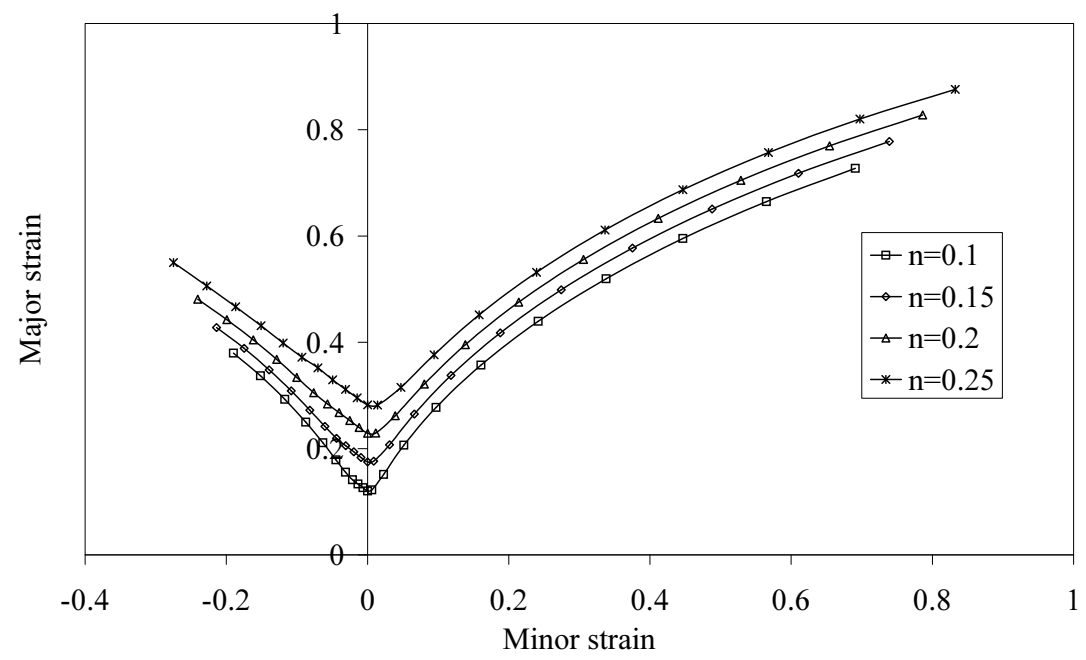

Figure 17. Effect of the strain hardening index $n$ on FLCs by the M-K model

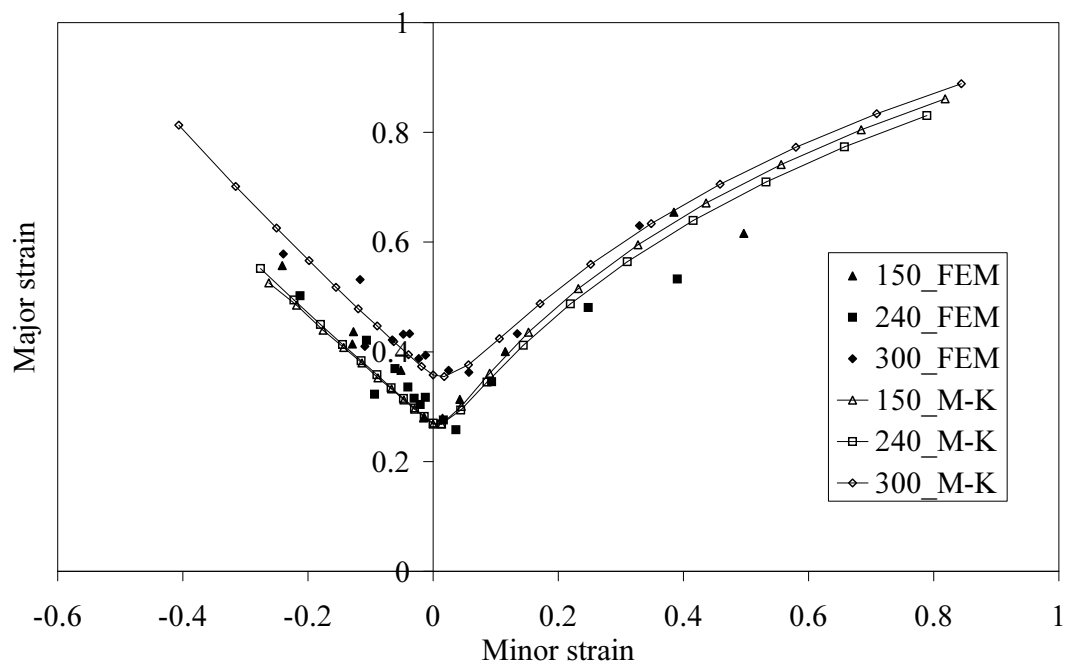

Figure 18. FLCs of AA5083 determined by the M-K model and by FEM 